\title{
Effect of an Educational Program on Care Burden and Quality of Life for Caregivers of Patients Diagnosed with Alzheimer's Disease
}

\author{
Hatice Tel Aydin \\ Sivas Cumhuriyet University Faculty of Health Sciences Department of Nursing, \\ Department of Internal Medicine Nursing. Sivas, Turkey \\ Havva Tel (Corresponding Author) \\ Sivas Cumhuriyet University Faculty of Health Sciences Department of Nursing, \\ Department of Mental Health and Disease Nursing. Sivas, Turkey \\ E-mail: havvatel@yahoo.com, havvatel@cumhuriyet.edu.tr \\ Nuran Guler \\ Sivas Cumhuriyet University Faculty of Health Sciences Department of Nursing, \\ Department of Public Health Nursing. Sivas, Turkey \\ Semra Kocatas \\ Sivas Cumhuriyet University Faculty of Health Sciences Department of Nursing, \\ Department of Public Health Nursing. Sivas, Turkey \\ Nurcan Akgul Gundogdu \\ Sivas Cumhuriyet University Faculty of Health Sciences Department of Nursing, \\ Department of Public Health Nursing. Sivas, Turkey
}

\begin{abstract}
Purpose: This study was undertaken to determine the effect of planned education upon the quality of life and care burden for caregivers of patients diagnosed with Alzheimer's disease.

Materials and Methods: This study, a planned pre-test post-test model with semi-experimental design, was undertaken with the caregivers for 60 patients diagnosed with Alzheimer's disease. Data were collected using Information Request Form, Zarit Burden Interview (ZBI) and WHOQOL-BREF Quality of Life Scales. Caregivers were divided into groups of 10 participants each and a 45-60 minute planned educational program on caring for Alzheimer's patients was provided to each group in 5 sessions. ZBI and Quality of Life Scales were again administered to the caregivers in the $1^{\text {st }}, 2^{\text {nd }}$, and $3^{\text {rd }}$ months following completion of the education.

Results: Results were assessed using percentage distributions, Chi-square test, and Pearson Correlation analysis. Care burden of caregivers for Alzheimer's patients decreased following the planned education and there was a significant and negative correlation between care burden and quality of life. As care burden decreased, quality of life increased $(\mathrm{p}<0.05)$.

Conclusion: A planned educational program reduced the care burden experienced by caregivers for Alzheimer's patients and affected their quality of life positively. It is recommended that planned education programs be reinforced with continuous counseling services in order to minimize the care burden experienced by these caregivers and to maximize their quality of life.
\end{abstract}

Keywords: Alzheimer disease; Caregiver; Care burden; Quality of life

DOI: $10.7176 / \mathrm{JHMN} / 75-06$

\section{Introduction}

Alzheimer's disease (AD) is a progressive and degenerative disease of the brain that causes multiple cognitive areas to become seriously impaired and results in a decline in functional abilities and behavioral changes. ${ }^{1}$ It is estimated that there are 20-25 million patients diagnosed with AD throughout the world. In the United States, one of every 8 individuals $\geq 65$ years is an Alzheimer's patient, while one of every 2 individuals $\geq 80$ years suffers from AD. It is anticipated that by 2050 the number of patients diagnosed with $\mathrm{AD}$ will reach 13.5 million. ${ }^{2,3}$ In Turkey there are nearly 480.000 patients diagnosed with $\mathrm{AD}$, and 
according to estimates by the World Health Organization, it is predicted that Turkey will be one of four countries in the world that will have the highest number of Alzheimer patients by $2050 .^{2}$

Since all of an individual's life functions are changed by $\mathrm{AD}$, individuals undergo progressive losses in physical and cognitive functioning, become unable to manage their lives by themselves and need the support of caregivers. ${ }^{4,5}$ Caregivers for patients diagnosed with $\mathrm{AD}$ are obliged to maximize activities of daily living of those for whom they provide care as well as their own. ${ }^{6}$ The caregiver role can produce changes in intra-familial roles, affect the social life of families negatively, lead to domestic problems, and affect caregivers' physical, and psychological health negatively. It can cause the caregivers to suffer from anxiety, depression, and social isolation, increase their use of health facilities and increase their need to use psychotropic medication. ${ }^{7-9}$ Therefore, it is imperative to be aware of the difficulties and needs of caregivers for patients with AD. Nurses play an important role in the home-care of individuals diagnosed with Alzheimer's. Nurses need to evaluate the individuals diagnosed with AD and their caregivers/families biologically, psychologically, socially and culturally. They need to explore homecare needs, find existing and potential problems, plan and provide education about the needs of the patients and their caregivers and provide them with counseling. ${ }^{10,11}$ Supporting caregivers of AD patients through planned educational programs and continuous counseling services will help both patients and family members lead better lives and improve their ability to cope with care-problems more actively.

\section{Materials and Methods}

\section{Study Design and Sample Selection}

This study was planned as a pre-test post-test model with a semi-experimental design. The subjects were the caregivers of $60 \mathrm{AD}$ patients who lived in the service area of a family health center in a district of Sivas Province, Turkey. Those participants who were aged $\geq 18$ years, were literate, had cared for an AD patient for at least six months, had no difficulties with communication and volunteered to participate in the study were recruited. The study was performed between the $1^{\text {st }}$ of May and the $31^{\text {st }}$ of October 2015 .

\section{Instruments}

\section{World Health Organization Quality of Life Scale-Short Form Turkish Version (WHOQOL-BREF TR)}

Validity and reliability tests of the scale, designed by the World Health Organization for Turkey, were performed by Fidaner et al. (1999). WHOQOL BREF-TR consists of 27 questions, one of which was a national question added during the Turkish validity and reliability studies. Subscales of WHOQOLBRIEF-TR consist of physical domain (questions 3, 4, 10, 15, 16, 17, and 18), psychological domain (questions 5, 6, 7, 11, 19, and 26), social domain (questions 20, 21, and 22) and environmental domain (questions 8, 9, 12, 13, 14, 23, 24, 25, and 27). All but the first two questions are used to calculate the various domain scores. The scale scores range from 0 to 20 , and as the scale scores increase, so does the quality of life. $^{12}$

\section{Burden Interview}

The Zarit Burden Interview (ZBI) was developed in 1980. Turkish validity and reliability tests of the scale were performed by İnci and Erdem (1999). This interview, which explores the effect of care-giving upon individuals' lives, is a five point Likert scale with 22 items. Scale scores range from 0 to 88 . Higher scores indicate a higher care burden. ${ }^{13}$

\section{Procedure}

The Information Request Form, Care-giving Difficulties Form, ZBI, and WHOQOL-BREF Quality of life scale were administered to the volunteers prior to the educational program. Caregivers were divided into groups of 10, and a 45-60 minute planned educational presentation about care of AD patients was provided to each group in 5 sessions. After completing the educational program, home visits were made to follow-up with the caregivers one, two, and three months after the program and the Care-giving Difficulties Form, ZBI, and Quality of Life scale were again administered.

\section{Data Analysis}

Study data was processed using SPSS 22.0; percentage distributions, Chi-square test, and Pearson Correlation analysis were employed. The Friedman and Wilcoxon tests were employed in order to understand the causes of difference between caregivers' quality of life and care burden.

\section{Ethics approval}

According to the Helsinki Declaration, verbal informed consent of the participants were obtained prior 
to the study by the Ethics Committee of Cumhuriyet University.

\section{Results}

A total of 60 caregivers were included in the study. The average age of the caregivers was $48.48 \pm 15.58$ years, and the length of care-giving varied between 1 and 15 years but averaged $4.66 \pm 3.54$ years. The following demographics describe the group: female $(81.7 \%)$, married $(81.7 \%)$, primary school degrees $(40.0 \%)$, housewives $(56.4 \%)$, family members $(58.3 \%)$, suffered from physical disease $(46.6 \%)$, suffered from psychological disease $(16.7 \%)$, had difficulty providing care $(91.7 \%)$ and received help and assistance from significant others $(56.7 \%)$.

Table 1 shows the distribution of caregivers' quality of life and ZBI scores in terms of pre-education and post-education month 1 , month 2 , and month 3 follow-ups. There was no statistically significant difference between the average scores of quality of life-subscales and the total scale score between the pre-education period and any of the follow-ups ( $p>0.005)$. The caregivers' physical, psychological, and environmental domain scores on the quality of life scale were similar and high, but the social domain score was considerably lower. However, there was a statistical difference in the average ZBI total scale scores when comparing pre-education to all three follow-ups $(\mathrm{p}<0.005)$. When intra-group differences were analyzed, a difference was found between pre-education and post-education follow-up on repeated measurements (pre-intervention to month 1 follow-up, month 1 to month 2 follow-up, month 1 to month 3 follow-up and month 2 to month 3 follow-up; $\mathrm{p}<0.005)$.

Table 2 presents the correlation between caregivers' average quality of life scores and the ZBI scales. A statistically significant and negative correlation existed between scores of Quality of Life psychological domain $(\mathrm{r}=-0.458, \mathrm{p}=0.000)$, social domain $(\mathrm{r}=-0.291, \mathrm{p}=0.016)$ and total quality of life scale score $(\mathrm{r}$ $=-0.475, \mathrm{p}=0.000)$ and the ZBI total score. As caregivers' scores in the three domains increased, the ZBI total score decreased. Since all of the participants had equal scores in the Quality of Life environmental domain, no correlation was calculated.

Table 1. Distribution of caregivers' quality of life and ZBI scores before and after education

\begin{tabular}{|c|c|c|c|c|c|}
\hline \multirow[t]{2}{*}{ Variables } & \multirow{2}{*}{$\begin{array}{l}\text { Pre-education } \\
\bar{x} \pm S S\end{array}$} & \multirow{2}{*}{$\begin{array}{l}1 \text { month } \\
\text { Post- education }\end{array}$} & \multirow{2}{*}{$\begin{array}{l}2 \text { months } \\
\text { Post- education } \\
\bar{x} \pm S S\end{array}$} & \multirow{2}{*}{$\begin{array}{c}3 \text { months } \\
\text { Post- education } \\
\bar{x} \pm S S\end{array}$} & \multirow[b]{2}{*}{$\mathrm{X}^{2} \quad \mathrm{p}$ value } \\
\hline & & & & & \\
\hline \multicolumn{6}{|c|}{ Average scores of WHOQOL Bref Quality of Life Scale } \\
\hline $\begin{array}{l}\text { Physical } \\
\text { Domain }\end{array}$ & $19.55 \pm 1.44$ & $19.19 \pm 1.94$ & $19.33 \pm 1.61$ & $19.25 \pm 1.73$ & $\begin{array}{l}X^{2}=5.23 \\
P=0.156\end{array}$ \\
\hline $\begin{array}{l}\text { Psychological } \\
\text { Domain }\end{array}$ & $18.30 \pm 2.33$ & $18.19 \pm 2.65$ & $18.47 \pm 2.24$ & $18.27 \pm 2.43$ & $\begin{array}{l}X^{2}=1.952 \\
p=0.582\end{array}$ \\
\hline Social Domain & $9.02 \pm 2.40$ & $8.79 \pm 2.40$ & $9.16 \pm 2.25$ & $9.01 \pm 2.30$ & $\begin{array}{l}X^{2}=4.071 \\
P=0.254\end{array}$ \\
\hline $\begin{array}{l}\text { Environmental } \\
\text { Domain }\end{array}$ & $19.79 \pm 1.14$ & $19.70 \pm 1.30$ & $19.73 \pm 2.18$ & $20.00 \pm 0.00$ & $\begin{array}{l}X^{2}=5.714 \\
p=0.126\end{array}$ \\
\hline $\begin{array}{l}\text { Quality of Life } \\
\text { Total Score }\end{array}$ & $66.69 \pm 4.58$ & $65.88 \pm 5.72$ & $66.70 \pm 4.43$ & $66.54 \pm 4.36$ & \multirow{2}{*}{$\begin{array}{l}X^{2}=1.848 \\
p=0.605\end{array}$} \\
\hline $\begin{array}{l}\text { Intra-group } \\
\text { differences }\end{array}$ & & & - & & \\
\hline \multicolumn{6}{|c|}{ Average scores of ZBI } \\
\hline Total score & $32.235 \pm 15.831$ & $35.455 \pm 16.291$ & $33.485 \pm 16.817$ & $31.323 \pm 16.240$ & \multirow{4}{*}{$\begin{array}{l}X^{2}=9.435 \\
p=0.024\end{array}$} \\
\hline \multicolumn{5}{|c|}{ Intra-group differences of ZBI total scores according to Month 1, Month 2, and Month 3 follow-ups } & \\
\hline \multirow{2}{*}{$\begin{array}{l}\text { Intra-group } \\
\text { differences }\end{array}$} & $\begin{array}{l}\text { Pre-intervention to } 1 \\
\text { month F/U }\end{array}$ & $\begin{array}{c}1 \text { month to } 2 \\
\text { month F/U }\end{array}$ & $\begin{array}{c}1 \text { month F/U to } 3 \\
\text { month F/U }\end{array}$ & $\begin{array}{c}2 \text { month to } 3 \text { month } \\
\text { F/U }\end{array}$ & \\
\hline & $\mathrm{p}=0.037$ & $\mathrm{p}=0.029$ & $\mathrm{p}=0.002$ & $\mathrm{p}=0.005$ & \\
\hline
\end{tabular}

$*$ Friedman test and Wilcoxan test were employed.

Table 2. Correlation between caregivers' quality of life and care burden

\begin{tabular}{|l|ll|}
\hline WHOQOL Bref Quality of life & \multicolumn{2}{|c|}{ ZBI } \\
\hline Physical Domain & $\mathrm{r}=-0.164$ & $\mathrm{p}=0.182$ \\
\hline Psychological Domain & $\mathrm{r}=-0.458$ & $\mathrm{p}=0.000$ \\
\hline Social Domain & $\mathrm{r}=-0.291$ & $\mathrm{p}=0.016$ \\
\hline Environmental Domain & $\mathrm{r}=-$ & $\mathrm{p}=-$ \\
\hline Quality of Life Total Score & $\mathrm{r}=-0.475$ & $\mathrm{p}=0.000$ \\
\hline
\end{tabular}

45 I P a g e 


\section{Discussion}

Individuals with $\mathrm{AD}$ are dependent upon others' care to continue their lives. This care can take place either at home or in an institution, but most patients are often cared for by a family member at home..$^{14}$ The average age of the caregivers in this study was $48.48 \pm 15.58$ years. Wang et al. found an average age for caregivers of $51.00 \pm 14.71$ years, while Montgomery et al. found an average age for caregivers of $53.90 \pm 11.00 .^{15,16}$ In the current study, the majority of caregivers were family members and housewives. Others have found that care is primarily provided by family members or significant others who are critically important in the patients' lives ${ }^{5}$, with a spouse or children holding the caregiver role. ${ }^{17}$ It has been reported that care burden frequency was 50\% during the Alzheimer's diagnostic phase, but care burden frequency rose to $58 \%$ twelve months following the diagnosis. ${ }^{18}$ It appears that as patients' behavioral and psychological problems increase, so does caregivers' burdens. ${ }^{19}$ Of the $46.6 \%$ of the caregivers suffering from physical diseases, $16.7 \%$ of them had psychological diseases and $56.7 \%$ of the caregivers received help and assistance from significant others while providing care. It has been noted that as caregivers' care associated stress and distress increased, their risk for developing physical and psychological disease as well as the prevalence of chronic physical disease and depression increased.$^{20}$ Caregivers experience a moderate level of anxiety and depression, but social support can relieve their physical and psychological difficulties. ${ }^{15}$ In the current study, 91.7\% of the caregivers expressed that they had difficulties providing patients' daily care. Akyar and Akdemir noted that $70 \%$ of those who cared for Alzheimer patients experienced difficulties providing that care. ${ }^{11}$ Not surprisingly, since caregivers experience physical, psychological, emotional, social, and economic problems while providing care, caregiver burden develops. ${ }^{21}$ In this study, we found that after the planned educational program, care burden was reduced among caregivers (Table 1). Gallagher-Thompson et al. emphasized that psychoeducational interventions given to caregivers improve their capacity to manage both mood and problem solving skills, and therefore decrease their depression and care burden considerably as well as improving their coping skills. ${ }^{22}$ In the current study it appears that these changes were the results of the educational program provided to the caregivers.

In the current study, we found a negative and significant correlation between caregivers' quality of life and ZBI. As the ZBI score decreased the total quality of life score and quality of life psychological domain and social domain scores increased; however, the environmental domain score remained rather low (Table 2). Care burden has been shown to influence AD patients' caregivers' quality of life negatively. ${ }^{21}$ Another study that assessed quality of life of caregivers of patients diagnosed with AD during hospitalization and 12 months following hospitalization suggested that caregivers' quality of life score decreased significantly 12 months after hospitalization. ${ }^{23}$ Ostwald et al. stated that easing caregivers' care burden produced improvements in their quality of life and affected patient outcomes positively. ${ }^{24}$ The results of this current study are in agreement with these findings.

In conclusion, this study was undertaken to determine the effect of a planned educational program on $\mathrm{AD}$ patients' caregivers' care burden and quality of life. We found that after the educational program, the care burden experienced by the caregivers had decreased and their quality of life was positively affected. To alleviate the care burden of the caregivers and to maintain their quality of life, it is recommended that planned educational programs be reinforced with continuous counseling services.

\section{Conflict of Interest}

The authors state that there is no potential conflict of interest in relation to the research.

\section{References}

1. Kang H, Myung W, Na DL, et al. Factors associated with caregiver burden in patients with Alzheimer's disease. Psychiatry Investig 2019;11(2):152-9. (PMID:24843370).

2. Alzheimer's Association [Internet] Available from:http://www.alzheimerdernegi.org.tr Accessed: 7.1.2014.

3. Hebert LE, Weuve J, Scherr PA, Evans DA.Alzheiemr's disease in the United States (2010-2050) estimated using the 2010 Consensus. Neurology 2013;80:1778-83. (PMID:23390181).

4. Fargo K, Bleiler L. Alzheimer's association report 2014 Alzheimer's disease facts and figures. Alzheimer's \& Demantia 2014;10:e47-e92.

5. Küçükgüçlü Ö. Alzheimer's disease and nursing care. Journal of Dementia 2003;3:86-92.

6. Pinquart M, Sörensen S. Associations of stressors and uplifts of caregiving with caregiver burden and depressive mood: a meta-analysis. J Gerontol B Psychol Sci 2003;58(2)112-28. (PMID:12646594). 
7. Barlas GU, Onan N. Communication with Alzheimer patients and their family. Journal of Ataturk University School of High Nursing 2008;11(4):105-11.

8. Mohamed S, Rosenheck R, Lyketsos K, Schneider LS. Caregiver burden in Alzheimer's disease:cross sectional and longitudinal patient correlates. Am J Geriatr Psychiatry 2010; 18(10):917-27. (PMID:20808108).

9. Sansoni J, Anderson KH, Varona LM, Varela G. Caregivers of Alzheimer's patients and factors influencing institutional of loved ones: some consideretions on existing literature. Ann Ig 2013;25(3):235-49. (PMID:23598807).

10. Smeltzer SC, Bare BG. Health care of older adult. Brunner and Suddarths Textbook of MedicalSurgical Nursing. 10th edition, LWW, USA 2003, pp 188-213.

11. Akyar İ, Akdemir N. Strains of caregivers of alzheimer patients. Hacettepe University Faculty of Health Sciences Journal of Nursing 2009;16(1):32-49.

12. Fidaner H, Elbi H, Fidaner C. Eser SY, Eser E, Göker E. Measuring quality of life, WHOQOL100 and WHOQOL-BREF. Journal of Psychiatry Psychology Psychopharmacology (3P)1999;7(Suppl 2):5-13.

13. İnci FH, Erdem M. Validity and reliability of the burden interview and its adaptation to Turkish. Journal of Ataturk University School of High Nursing 2008;11(4):85-95.

14. Gruffydd E, Randle J. Alzheimer's disease and the psychosocial burden for caregivers. Community Pract 2006;79(1):15-8.(PMID:16435497).

15. Wang Z, Ma C, Han H, et al. Caregiver burden in Alzheimer's disease: moderation effects of social support and mediation effects of positive aspects of caregiving. Int $\mathrm{J}$ Geriatr Psychiatry 2018;33(9):1198-206.(PMID:29856091).

16. Montgomery W, Goren A, Kahle-Wrobleski K, Nakamura T, Ueda K. Alzheimer's disease severity and its assocation with patient and caregiver quality of life in Japan: results of a community-based survey. BMC Geriartics 2018; 18(1):141-52. (PMID:29898679).

17. Reed C, Belger M, Dell'Agnello G, et al. Caregiver burden in Alzheimer's disease: differential associations in adult-child and spousal caregivers in the GERAS Observational study. Dement Geriatr Cogn Dis Extra 2014;4(1):51-64. (PMID: 24711814).

18. Brodaty H, Woodward M, Boundy K, Ames D, Balshaw R. Prevalence and predictors of burden in caregivers of people with Dementia. Am J Geriatr Psychiatry 2014;22(8):756-65. (PMID:24012226).

19. Kamiya M, Sakurai T, Ogama N, Maki Y, Toba K. Factors associated with increased caregiver's burden in several cognitive stages of Alzheimer's disease. Geriatr Gerontol Int 2014; 14(Suppl 2):45-55. (PMID:24650065).

20. Bonnel WB. Not gone and not forgotten: a spouse's experience of late-stage Alzheimer's disease. J Psychosoc Nurs Ment Health Serv 1996;34(8):23-7. (PMID:8856601).

21. Adelman RD, Tmanova LL, Delgado D, Dion S, Lanchs MS. Caregiver burden: a clinical review. JAMA 2014;311(10):1052-1060. (PMID:24618967).

22. Gallagher-Thompson D, Lovett S, Rose J, et al. Impact of psychoeducational interventions on distressed family caregivers. Journal of Clinical Geropsychology 2000;6(2):91-110.

23. Garzón-Maldonado FJ, Gutiérrez-Bedmar M, García-Casares N, Pérez-Errázquin F, GallardoTur A, Martínez-Valle Torres MD. Health-related quality of life in caregivers of patients with Alzheimer disease. Neurologia 2017;32(8):508-15. (PMID:27126568).

24. Ostwald SK, Hepburn KW, Caron W, Burns T, Mantell R. Reducing care-giver burden: a randomized psychoeducational intervention for caregivers of person with demantia. The Gerontologist 1999;39(3):299-309. (PMID:10396888). 